\title{
A Structure-Based 3D-QSAR(CoMSIA) Study on a Series of Aryl Diketoacids (ADK) as Inhibitors of HCV RNA-dependent RNA Polymerase
}

\author{
Jinyoung Kim, Jin Hee Han, and Youhoon Chong \\ Division of Biosciences and Biotechnology, Konkuk University, Seonl 143-701, Korea. "E-mail: chongy@konkukackr \\ Received Angust 9, 2006
}

Key Words : IICV RdRp, $\Lambda$ ryl diketoacid ( $\Lambda$ DK), FlexX-Pharm, CoMSI $\Lambda$

The diketoacid moiety of aryl $\alpha, \gamma$-diketoacids (ADKs, Fig. 1) proved essential for antiviral activity against hepatitis $C$ virus (HCV) RNA-dependent RNA polymerase (RdRp), and structure-activity optimization studies have led to the identification of an $\mathrm{ADK}$ inhibitor as one of the most potent HCV RdRp inhibitors reported. ${ }^{1}$ However, in spite of the extensive structure-activity relationship study, it has not been clear what controls the binding affinity of $\mathrm{ADK}$ analogues to the target enzyme. ${ }^{2}$

$3 \mathrm{D}-\mathrm{QSAR}$ techniques, such as comparative molecular force field analysis (CoMFA) ${ }^{3}$ and comparative molecular similarity indices analysis (COMSIA), are based on the experimental structure-activity relationship on specific biomolecule-ligand pair. This method is based only on the ligand structure and thus the spatial arrangement (or aligiment) is crucial in determining the accuracy of these approaches. In case of ADK analogues, it is obvious that the common structural unit, diketoacid moiety, could be used as a template for atom based alignment. However, the atombased fit (using atoms of diketoacid) produced poor CoMFA and CoMSLA results (data not shown) presumably due to the highly flexible alkyl linker which connects two aromatic rings of $\mathrm{ADK}$ analogues (Fig. 1). This result implies that $\mathrm{ADK}$ analogues bind to the target enzyme in a characteristic active conformation, which cannot be identified by investigation of the ligand structures alone. Thus, $\mathrm{ADK}$ analogues should be docked into the binding site of the target enzyme to provide the active conformations, which can be used for the structure-based alignment. However, the lack of information about the binding site of $\mathrm{ADK}$ analogues at the target enzyme limits this approach. In this study, the binding site of $\mathrm{ADK}$ analogues in the HCV RdRp was proposed by using an unusual crystal structure of rUTP-HCV RdRp complex (PDB ID 1GX6) and structural similarity between rUTP and $\mathrm{ADK}$. The $\mathrm{ADK}$ analogues were aligned by docking into the binding site, and a stucture-based $3 \mathrm{D}-\mathrm{QSAR}$ study was performed to conelate the biological activities of ADKs with their three-dimensional structures.

The diketoacid moiety is famous for its metal-binding ability, ${ }^{6}$ and $\mathrm{ADK}$ analogues are known to bind the divalent metal jons at the active site of HCV RdRp. ${ }^{7.8}$ However, it remains unsolved how $\mathrm{ADK}$ analogues bind to the active site of a polymerase enzyme without formation of the complementary base pairing with the RNA template chain. Additionally, it has been speculated that $\mathrm{ADK}$ analogues might have different binding site around the active site of
HCV RdRp. Recently, Bressanelli er $a l^{5}$ reported the unusual crystal structure of rUTP bound to HCV RdRp and it shows that rUTP binding site is quite different from the active site with the base (uracil) hydrogen atoms bonded to the polypeptide main chain (PDB ID 1GX6). This altemative binding mode of rUTP is artificial in the sense that rUTP cannot bind in such a way in the presence of template, but it is conceivable that molecules with higher binding affinity to the rUTP-binding site in this mode can inhibit the catalytic activity of the enzyme. Thus, we set out to investigate the characteristic binding mode of rUTP, which resulted in construction of a pharmacophore model composed of three key interactions between rUTP and HCV RdRp (Fig. 2): (a) electrostatic interaction with two divalent metal ions $\left(\mathrm{Mn}^{2+}\right)$, (b) H-bonding of triphosphate moiety to nearby amino acid residues (Phe224, Asp225), (c) H-bonding between uracil

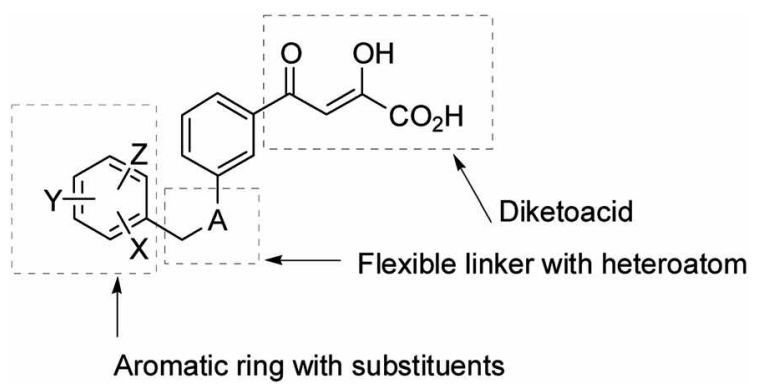

Figure 1. General structure of $A D K$ analogues.

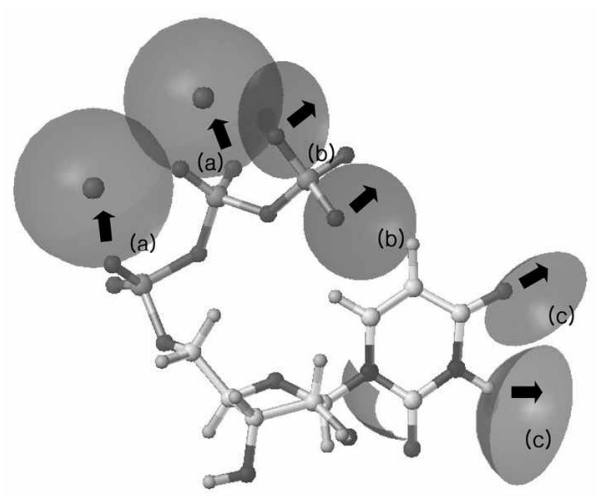

Figure 2. Most critical interactions between rUTT and HCV RdRp used as guidelines for docking by FlexX-Pharm: (a) Electrostatic interaction with $\mathrm{Mn}^{2+}$; (b) H-bonding with Phc224 and $\Lambda \mathrm{sp} 225$; (c) $\mathrm{H}$-bonding with Leu 159 . Shaded dishes indicate rUTP-binding site of the enzyme characterized by these conditions. 

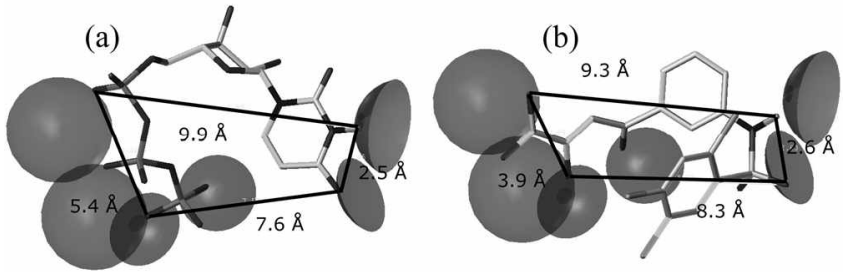

Figure 3. Comparison of the pharmacophores of (a) rUTP and (b) ADK (1). Shaded dishes indicate specific interactions around the pharmacophore with the enzyme residues: electrostatic interaction with divalent metal ions, $\mathrm{H}$-bond acceptors, and H-bond donors.

base and Leu159. To our surprise, the generated pharmacophore has an interesting match with an ADK molecule of which diketoacid moiety and $\mathrm{H}$-bond donor/acceptor are in good three dimensional agreements with the triphosphate and uracil base of the rUTP, respectively (Fig. 3). Based on the structural similarity of the pharmacophore model of rUTP and $\mathrm{ADK}$, we assumed that $\mathrm{ADK}$ might bind to the same site of rUTP found in the crystal structure of 1GX6. Thus, twenty structurally distinct ADK analogues taken from the literature ${ }^{2 a}$ (Fig. 4) were docked into the rUTP binding site by the pharmacophore-guided docking (FlexXPharm, SYBYL 7.2$)^{10}$ protocol to generate structure-based alignment of $\mathrm{ADK}$ analogues. The results of the superimposed images of 20 ligand structures docked at the ADK binding site of the HCV RdRp are shown in Figure 5.

With the structure-based ligand alignment in hand, we attempted 3D-QSAR study by using CoMSIA method. The basic principle of CoMSIA is the same as that of CoMFA, but CoMSIA includes some additional descriptors such as hydrophobicity, hydrogen bond donor and hydrogen bond acceptor. ${ }^{4}$ In this study, CoMSIA was chosen as the method of choice in preference to CoMFA because both hydrophobic and hydrogen bonding interaction fields were included in the CoMSIA model, which might play a key role in determining the binding affinity of $\mathrm{ADK}$ analogues to the HCV RdRp. The regression analysis of CoMSIA field energies was performed using the partial least squares (PLS) algorithm with the leave-one-out (LOO) method adopted for cross validation. The results obtained from the PLS analysis are summarized in Table 1. CoMSIA with 20 molecules in the training set produced a cross-validated $r$ of 0.966 with minimum standard error of estimation (SEE, 0.215) (Table 1). This analysis was used for the final non-cross-validated run, giving a good correlation coefficient ( $q^{2}$ value of 0.525$)$ (Table 1). Table 1 also shows high hydrophobic contribution $(0.530)$ to the CoMSIA model compared with hydrogen bond donor or acceptor, which suggests that the contribution from the hydrophobic interaction is the key to the binding affinity of ADK analogues. Moreover, as the diketoacid moiety and hydrogen bond donor (or acceptor) are the common structural units of ADK analogues (Fig. I), the contribution of hydrophobic field to the final CoMSIA model becomes even more important.

The actual and calculated inhibitory activities and the residual values for training set molecules are given in Table 2 , and the plot of actual $\mathrm{pIC}_{50}$ values versus predicted $\mathrm{pIC}_{50}$<smiles>O=C(O)/C=C(\O)c1cccc(NS(=O)(=O)c2cc(Cl)c(Cl)cc2Cl)c1</smiles><smiles>N#Cc1ccc(Br)cc1Oc1cccc(C(=O)C=C(O)C(=O)O)c1</smiles><smiles>N#CCCCCn1cccc1C=C(O)C(=O)O</smiles><smiles>O=C(O)/C(O)=C/C(=O)c1cccc(Oc2ccccc2)c1</smiles><smiles>O=C(O)/C=C(\O)c1cccc(OCc2cccc(Oc3ccccc3)c2)c1</smiles><smiles>O=C(O)C(=CC(=O)c1cccc(OCc2ccsc2CO)c1)C(=O)O</smiles><smiles>O=C(O)C(=O)Nc1cccc(C(=O)C=C(O)C(=O)O)c1</smiles>

17<smiles>N#Cc1ccccc1COc1cc(O)cc(C(=O)C=C(O)C(=O)O)c1</smiles><smiles>O=C(O)C=C(O)c1cccc(O)c1</smiles><smiles>COc1cccc(C(=O)C=C(O)C(=O)O)c1</smiles>

18<smiles>N#Cc1ccccc1Cn1cccc1C=C(O)C(=O)O</smiles><smiles>O=C(O)/C=C(\O)c1cc2c(s1)-c1cc(F)ccc1OC2</smiles><smiles>O=C(O)/C(O)=C/C(=O)c1cccc(NS(=O)(=O)c2ccc(Cl)c(Cl)c2)c1</smiles><smiles>O=C(O)C=C(O)c1cc(O)cc(OCc2ccccc2)c1</smiles><smiles>COc1ccc(Cn2cccc2C(=O)C=C(O)C(=O)O)cc1</smiles>

19
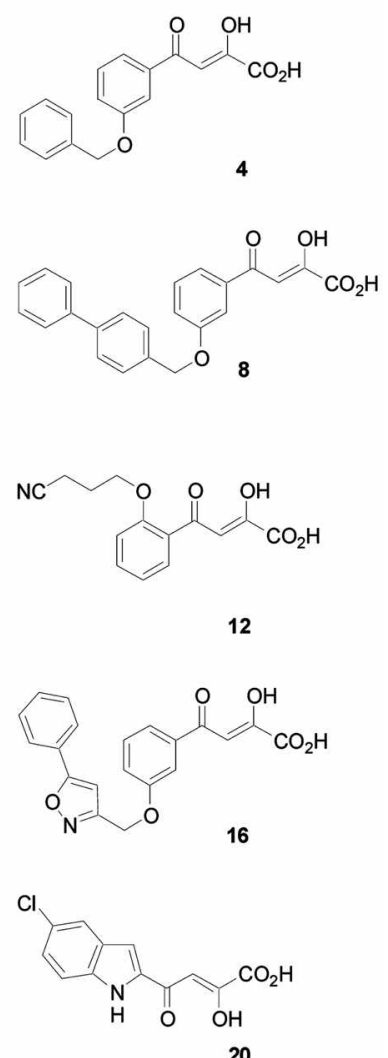

Figure 4. Structures of ADK analogues docked at HCV RdRp by FlexX-Pharm. 


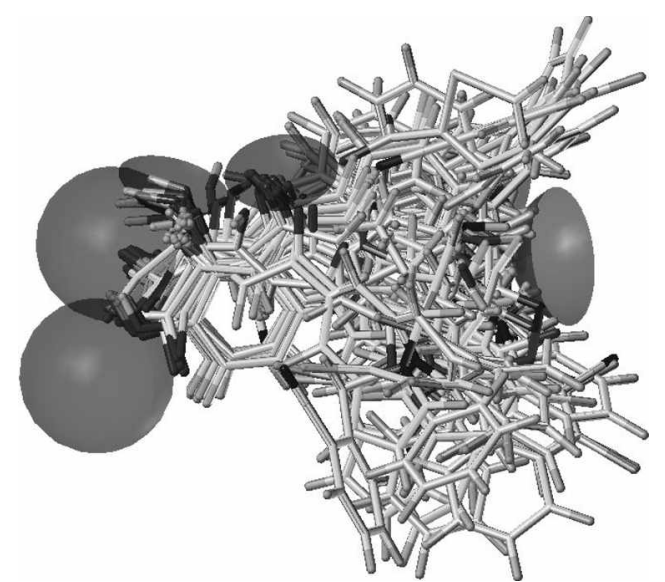

Figure 5. Superimposed images of $20 \mathrm{ADK}$ analogues after FlexXPharm docking.

Table 1. The results of PLS analysis in the Training Set using CoMSIA

\begin{tabular}{|c|c|c|}
\hline \multicolumn{2}{|c|}{ Field } & \multirow{2}{*}{$\frac{\mathrm{HDA}^{4}}{0.966}$} \\
\hline & $r$ & \\
\hline PLS & Components & 4 \\
\hline \multirow[t]{2}{*}{ Analysis } & SEE & 0.215 \\
\hline & $q^{2}$ & 0.525 \\
\hline \multirow{3}{*}{ Contribution } & Hydrophobic & 0.530 \\
\hline & H Bond Donor & 0.228 \\
\hline & H Bond Acceptor & 0.242 \\
\hline
\end{tabular}

$T=$ hydrophobic, $\mathrm{D}=$ hydrogen bond donor, $\mathrm{A}=$ hydrogen bond acceptor

Table 2. Actual and predicted activitics $\left(\mathrm{pIC}_{50}\right)$ of the training set molecules

\begin{tabular}{|c|c|c|c|c|c|c|c|}
\hline \multicolumn{4}{|c|}{$\mathrm{plC}_{50}$} & \multicolumn{4}{|c|}{$\mathrm{plC}_{50}$} \\
\hline Compd. & Actual & Pred. & Residual & Compd. & Actual & Pred. & Residual \\
\hline 1 & 7.83 & 8.04 & -0.21 & 11 & 6.85 & 6.69 & 0.16 \\
\hline 2 & 7 & 6.67 & 0.24 & 12 & 6.42 & 6.61 & 0.26 \\
\hline 3 & 5.2 & 5.35 & -0.15 & 13 & 6.02 & 5.86 & 0.16 \\
\hline 4 & 5.1 & 5.04 & 0.06 & 14 & 6 & 5.9 & 0.1 \\
\hline 5 & 4.89 & 5.02 & -0.13 & 15 & 5.85 & 5.94 & -0.09 \\
\hline 6 & 4.72 & 4.85 & -0.13 & 16 & 5.22 & 5.21 & 0.01 \\
\hline 7 & 4.57 & 4.5 & 0.07 & 17 & 4.72 & 4.52 & 0.2 \\
\hline 8 & 4.3 & 4.25 & 0.05 & 18 & 4.4 & 4.95 & -0.55 \\
\hline 9 & 4.3 & 4.31 & -0.01 & 19 & 5.23 & 5.13 & 0.1 \\
\hline 10 & 7 & 7.15 & -0.15 & 20 & 5.12 & 5.12 & 0 \\
\hline
\end{tabular}

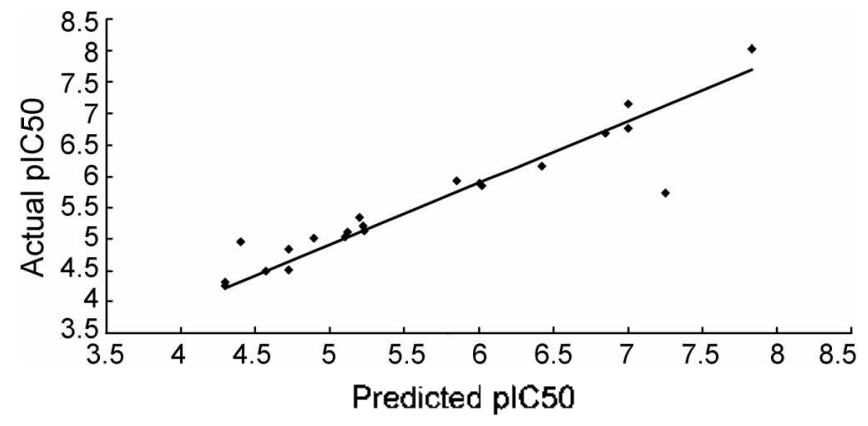

Figure 6. Comparison of actual vs predicted $\mathrm{pIC}_{50}$

is shown in Figure 6. As a result, both of them indicate good predictivity of the COMSIA model.

Graphical representations of CoMSIA maps obtained by the field type "stDev*coeff" are displayed in Figure 7. The contour maps were superimposed on the most active compound 1 shown as a capped stick. The regions where hydrogen bond donor or acceptor is associated with enhanced affinity are found near the diketoacid moiety and heteroatom linker part (amino or sulfonamino group) (Figs. $7 \mathrm{a}$ and $7 \mathrm{~b}$ ). Thus, hydrogen bonding interaction seems to be essential for ADK analogues to bind to the target enzyme. However, the hydrogen bonding interaction is not likely to be involved in fine-tuning of binding affinities of $\mathrm{ADK}$ analogues as the diketoacid and heteroatom linker moieties are the common structural units of ADK analogues (Fig. 1). On the other hand, dark grey contour region where hydrophobicity is associated with enhanced affinity is located near the aromatic ring, which suggests that substitution of the aromatic ring with bulky substituents would enhance the binding affinity of ADK analogues (Fig. 7c). It is also worth while to note that the light grey contour region where hydrophobicity is associated with diminished affinity is found around the diketoacid as well as the heteroatom linker part, which suggests that substitutions at these positions would not be beneficial (Fig. $7 \mathrm{c}$ ).

To further validate our results, four compounds ${ }^{2 a}$ with $\mathrm{pIC}_{50}$ range between 4.77 and 7.25 which were not included in the training set were assigned as test set molecules and their biological activities were predicted from the PLS equation derived from CoMSIA model. Predicted and actual activities of test set molecules are summarized in Table 3. Predicted $\mathrm{pIC}_{50}$ values agree well with the experimental ones $\left(r_{\text {pred }}^{2}=0.797\right)$ with average deviation of 0.44 , which suggests that our model is good for prediction of the $\mathrm{pIC}_{50}$ (a)

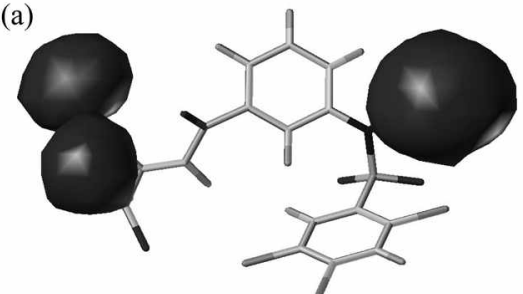

(b)

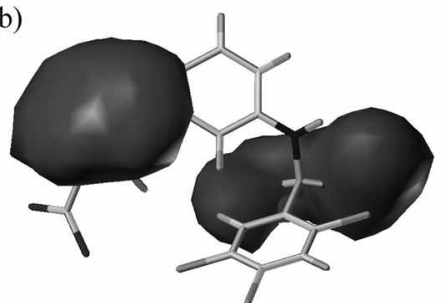

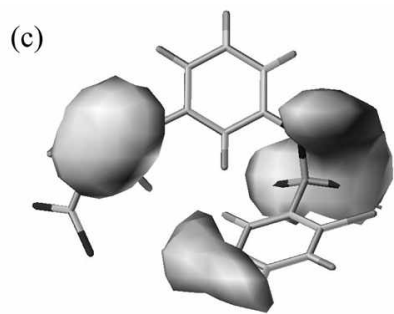

Figure 7. (a) Superposition of the CoMSIA hydrogen bond donor contour plots; (b) Superposition of the CoMSIA hydrogen bond acceptor contour plots: (c) Superposition of the CoMSIA hydrophobic contour plots. 
Table 3. Actual and predicted activities ( $\mathrm{pIC}_{50}$ ) of test set molecules

Compd.

values of ADK analogues against HCV RdRp.

In summary, a CoMSIA model constructed by structurebased 3D-QSAR study could be successfully applied to predict the biological activity of $\mathrm{ADK}$ analogues. The binding affinity of ADK analogues are found to be highly dependent upon the hydrogen bonding interaction as well as hydrophobic interaction around the aromatic ring of $\mathrm{ADK}$ analogues. In particular, the CoMSIA model proposes that the hydrophobic aromatic ring play a key role in determining the antiviral activity of ADK analogues. Thus, hydrophobic substituents around the aromatic ring reinforce hydrophobic interaction with the target enzyme, whereas the lack of aromatic substitution and thereby insufficient size of the inhibitor molecule can be primarily ascribed to their inability to bind to the hydrophobic binding site.

\section{Experimental Section}

All calculations were done on a Linux Enterprise OS using SYBYL 7.2 software packages. ${ }^{10}$

Data set. ADK molecules were prepared using the sketch module in the SYBYL package and conformational searches were performed by a grid search, which calculates energies by systematically changing the dihedral angles of each ligand using standard TRIPOS force field. ${ }^{11}$ The lowest energy structures were selected as conformers for the pharnacophore-guided docking (FlexX-Pharm) studies. Finally, all ligands were fully optimized using the standard TRIPOS force field with Gästeiger-Hückel charges ${ }^{12}$ until the energy gradient converged below $0.05 \mathrm{Kcal} / \mathrm{mol}$.

Docking with FlexX and FlexX-Pharm. Three dimensional crystal structure of HCV RdRp was obtained from the protein data bank (PDB code IGX6). Active site of the enzyme was defined as all the residues within $15^{\prime}$ of the bound ligand and two metal ions. Standard parameters were used as implemented in SYBYL 7.2 package. Formal charges and the particle concept options were always checked. In each case, a maximum of 100 poses were saved for each docked compound, although typically many fewer poses (30) were saved because biased sampling was used in the docking process.

PLS analysis. The regression analysis of CoMSIA field energies was performed using the partial least squares (PLS) algorithm with the leave-one-out (LOO) method adopted for cross validation. The optimum number of components to be used in conventional analyses was chosen from (i) the analysis with the highest cross validated $r$ value, and (ii) the model with the smallest standard error of prediction for component models with identical $r^{2}$ values. Final analysis was carried out to calculate the conventional $r^{2}\left(q^{2}\right)$ value using the optimum number of components. This analysis was used for the final non-cross-validated run.

Acknowledgments. This work was supported by grant KRF-2006-003-C00176 from the Korea Research Foundation, Republic of Korea (MOEHRD, Basic Research Promotion Fund) and by grants from Biogreen 21 (Korea Ministry of Agriculture and Forestry), and the second Brain Korea 21 (Korea Ministry of Education). Jinyoung Kim is supported by the second Brain Korea 21.

\section{References}

I. Summa, V.; Petrocchi, A.; Pace, P; Matassa, V. G.; De Francesco, R.; Altamura, S.; Tomei, L.; Koch, W.; Neuner, P. J. Med. Chem. $2004,47,14$.

2. (a) Di Santo, R.; Fermeglia, M.; Ferrone, M.; Silvia Paneni, M.; Costi, R.; Artico, M.; Roux, A.; Gabriele, M.; Tardif, K. D.; Siddiqui, A.; Pricl, S. J. Med. Chem, 2005, 48, 6304. (b) Altamura, S.; Tomei, L.; Koch, U.; Neuner, P. J.; Summa, V. PCT Int. Appl. WO 200006529, 2000; CAN 132: 132323, 2000.

3. (a) Clark, M.; Cramer III, R. D.; Jones, D. M.; Patterson, D. E.; Simeroth, P. E. Tetrahedron Coniput. Methodol 1990, 3, 47. (b) San Juan, A. A.; Cho, S. J. Bull. Korean Chem. Sac. 2005, 26, 952.

4. (a) Klebe, G.; Abraham, U.; Mietzner, T. J. Med. Chem, 1994, 37 , 4130 . (b) Kim, J.; Lee, M.; Kang, S.-Y.; Park, J.; Lim, Y.; Koh, D.; Park, K. H.; Chong, Y, Bull. Kor. Chem. Soc. 2006, 27, 1025.

5. Bressanelli, S.; Tomei, L.; Rey, F. A.; De Francesco, R. J. Virol. 2002, 76, 3482.

6. Sechi, M.; Bacchi, A.; Carcelli, M.; Compari, C.; Duce, E.; Fisicaro, E.; Rogolino, D.; Gales, P.; Derndas, M.; Al-Mawsawi, L. Q.; Neamati, N. J. Med. Chem. 2006, 49, 4248.

7. Grobler, J. A.; Stillmock, K.; Hu, B.; Witmer, M.; Felock, P.; Espeseth, A. S.; Wolfe, A.; Egbertson, M.; Bourgeois, M.; Melaned, J. Proc. Natl. Acad. Sci. USA 2002, 99, 6661.

8. Pais, G. C.; Zhang. X.; Marchand, C. Neamati, N.; Cowansage, K.; Svarovskaia, E. S.; Pathak, V. K.; Tang, Y.; Nicklaus, M.; Pommier, Y.J. Med. Chem, 2002, 45, 3184.

9. Hindle, S. A.; Rarey, M.; Buning, C.; Lengaue, T, J. Conput.Aided Mol. Des. 2002, 16, 129.

10. SYBYL Molectlar Modeling Software; Tripos Inc.: St. Louis, MO 2002.

11. Mohammadi, M.; McMahon, G; Sur, L.; Tang, C.; Hir1h, P.; Yeh, B. K.; Hubbard, S. R.; Schlessinger, J. Science 1997, 276, 955.

12. Gasteiger, J.; Marsili, M. Tetrahedron 1980, 36, 3219. 